Overview of the Australian National Mental Health Survey. British Journal of Psychiatry, 178, 145-153.

_ , Issakidis, C. \& Carter, G. (200Ib) Shortfall in mental health service utilisation. British Journal of Psychiatry, 179, 417-425.

Meadows, G., Fossey, E., Harvey, C. A., et al

(2000a) The assessment of perceived need. In Unmet

Need in Psychiatry (eds G. Andrews \& S. Henderson)

Cambridge: Cambridge University Press.
_ , Harvey, C., Fossey, E., et al (2000b) Assessing perceived need for mental health care in a community survey: the development of the Perceived Need for Care Questionnaire (PNCQ). Social Psychiatry and Psychiatric Epidemiology, 35, 427-435.

G. Andrews University of New South Wales, School of Psychiatry, Clinical Research Unit for
Anxiety Disorders, 299 Forbes Street, Darlinghurst, NSW 2010, Australia

S. Henderson Centre for Mental Health Research, Australian National University, Canberra, Australia

W. Hall National Drug and Alcohol Research Centre, University of New South Wales, Sydney, Australia

\title{
One hundred years ago
}

\section{Lunacy in Scotland}

THE forty-third annual report of the General Board of Commissioners in Lunacy for Scotland consists of 18 sections and 4 appendices.

\section{Number of insane persons}

On January 1st, 1901, there were 15,899 insane persons in Scotland, of whom 2,395 were maintained from private sources, 13,458 by parochial rates, and 46 at the expense of the State. Since 1858 the number of lunatics under the jurisdiction of the
Board has shown a total increase of 10,075 , or 173 per cent. The increase of the population during the same period has been 42 per cent. The proportion of pauper lunatics per 100,000 of population shows an almost steady increase since 1858 , and at the beginning of this year, attained its highest figure of 308 , as against the nex highest -304 , which was attained last year. During the last 27 years the proportion of private patients to population remains practically the same. The whole number of voluntary patients admitted into asylums in 1900 was 84 . The Commissioners continue to be of opinion that it is a useful provision of the law which permits persons who desire to place themselves under care in an asylum to do so in a way which is not attended with troublesome or disagreeable formalities.

\section{REFERENCE}

British Medical Journal, 4 January 1902

Researched by Henry Rollin, Emeritus Consultant Psychiatrist, Horton Hospital, Epsom, Surrey 